\title{
A micro-method for peripheral leucocyte migration in tuberculin sensitivity
}

\author{
K. FEDERLIN'1, R. N. MAINI, A. S. RUSSELL, AND D. C. DUMONDE \\ From the Divisions of Clinical Research and Immunology, Kennedy Institute of Rheumatology, \\ Hammersmith, London
}

SYNOPSIS Inhibition of buffy layer peripheral leucocyte migration by tuberculin purified protein derivative (PPD) from micro-capillaries mounted in small tissue culture chambers correlates in all cases with a positive Mantoux test. This quick and reproducible test of cellular hypersensitivity in man requires only $5-15 \mathrm{ml}$ of blood and is applicable for study in children and in clinical situations where repeated monitoring of cellular immunity may be required.

There is much current interest in the clinical significance of cellular hypersensitivity, for example, in chronic intracellular infections, connective tissue and chronic granulomatous diseases, transplantation and tumour immunity, and in immune deficiency states. For clinical investigation, there is need for a widely applicable test of specific cellular hypersensitivity in vitro. When sensitized lymphocytes interact with specific antigen, soluble mediators of cellular hypersensitivity are generated (Dumonde, 1970). The ability of these soluble factors to inhibit the migration of cultured macrophages and leucocytes provides one measure of cellular hypersensitivity (see Dumonde and Maini, 1971). In this paper we describe an improved method for detecting the inhibition of leucocyte migration by specific antigen which is based on the technique of Bendixen and Søborg (1969). Our technical improvements employ small slide chambers and micro-capillaries which together save on precious antigens and on the amounts of blood required for a migration test and permit more rapid assembly and execution of the test system.

\section{Materials and Methods}

Fifteen volunteer Mantoux-positive and eight Mantoux-negative subjects were studied. Blood was taken in a plastic syringe with 20 units of preservative-free heparin/ml of blood and mixed by rotating the syringe for one minute; the blood was then allowed to sediment at $37^{\circ} \mathrm{C}$ for about

'Present address: Zentrum fuer Innere Medizin und Kinderheilkunde, Universitaet Ulm, Steinhoevelstr. 9, D 79 Ulm, Germany.

Received for publication 8 March 1971.
$90 \mathrm{~min}$ in a non-wettable plastic sterile test tube, by which time the red cells had settled at the bottom, leaving a leucocyte-rich plasma layer above. The leucocytes were centrifuged at room temperature at $150 \mathrm{~g}$ for $10 \mathrm{~min}$, washed thrice in Waymouth's medium containing $10 \%$ horse serum, and resuspended in the medium at $7 \times 10^{7}$ leucocytes $/ \mathrm{ml}$. Micro-capillaries (20 $\mu$ l volume, Drummond microcaps $^{2}$ ) were cut in two equal parts to give a $10 \mu \mathrm{l}$ capillary size and these were filled with the leucocyte suspension and plugged at one end with wax. The $10 \mu \mathrm{l}$ capillaries were placed in a test tube and spun at $600 \mathrm{~g}$ for five min; these were cut at the cell-fluid interface and were mounted on silicone dabs in the chambers. The chamber consisted of a plastic ring $16 \mathrm{~mm}$ diameter, $2 \mathrm{~mm}$ high, mounted with silicone grease on an ether-cleaned glass slide (Fig. 1a). The upper surface of the ring was greased with silicone to receive a coverslip and the open chamber was sterilized with ultraviolet light. Two capillaries per chamber were mounted on silicone dabs placed on the slide within the ring, and the chamber was filled with Waymouth's medium containing $10 \%$ horse serum alone (control) or with Waymouth's medium containing $10 \%$ horse serum and 300,30 , and $3 \mu \mathrm{l} / \mathrm{ml}$ of preservative-free PPD (Weybridge). Chambers were filled until a slight convex surface of the fluid was obtained (approximately $0.35 \mathrm{ml}$ ) and a sterile coverslip was placed on the ring to give an airtight seal.

The chambers were incubated for 18 hours at $37^{\circ} \mathrm{C}$ in an ordinary incubator and during this period the leucocytes in the micro-capillaries migrated out. Twenty-five to 30 capillaries could be 'Supplied by Shandon Scientific Ltd, Willesden, London, NW10. 


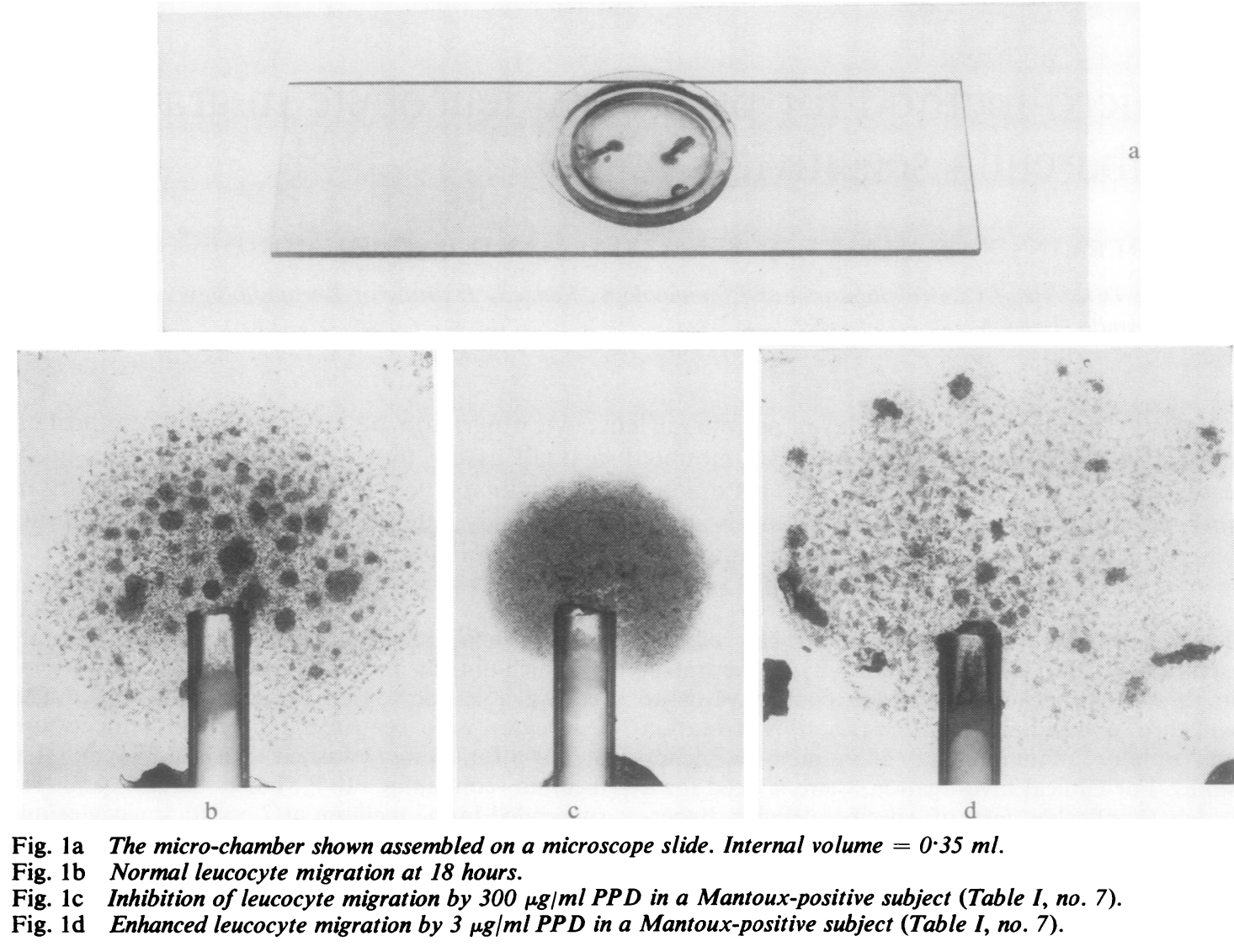

obtained from $15 \mathrm{ml}$ of blood and therefore in most cases six capillaries, each without antigen and at each of the three concentrations of antigen, could be set up. In the case of children, smaller amounts of blood $(5-10 \mathrm{ml})$ could be used without sacrificing accuracy of results, still allowing capillaries at each antigen dilution in triplicate or quadruplicate.

After 18 hours' incubation, the migration area of the leucocytes was mapped by projection microscopy and measured by planimetry. The results were expressed as a 'migration index', which is the ratio:

Mean migration area in presence of antigen Mean migration area in presence of culture medium alone

Red cell contamination of the leucocyte suspension was usually less than 1:1 and no particular advantage in higher purity (which could be achieved by differential centrifugation or by flash-lysis with Tris-buffered $\mathrm{NH} 4 \mathrm{Cl}$ ) was obvious in the sensitivity of the test. Indeed, red-cell-free leucocyte migrations had a less distinct image on projection and made it harder to read the result.
The following were of importance in obtaining good results: a very clean glass slide; cleanly cut capillaries which were not allowed to 'dry' after cutting; exclusion of air bubbles; and a strict $p H$ adjustment of the tissue culture medium to between $7 \cdot 2$ and $7 \cdot 4$.

\section{Results}

In the absence of antigen, leucocyte migration occurred as shown in the photograph (Fig. 1b). At a PPD concentration of $300 \mu \mathrm{g} / \mathrm{ml}$, leucocytes obtained from subjects who were Mantoux positive (1:100 or $1: 1,000$ Old Tuberculin) showed inhibition of migration (Fig. 1c) as reflected by a migration index below 0.8 in every case (Fig. 2, Table I). This contrasted with the results seen in donors who were Mantoux negative at $1: 100$ in whom the migration index at the corresponding antigen concentration varied between 0.85 and $1 \cdot 12$. Within each set of six replicate capillaries, it was unusual for migration areas to vary by more than $\pm 10 \%$, and by inspection, any single large variation could 


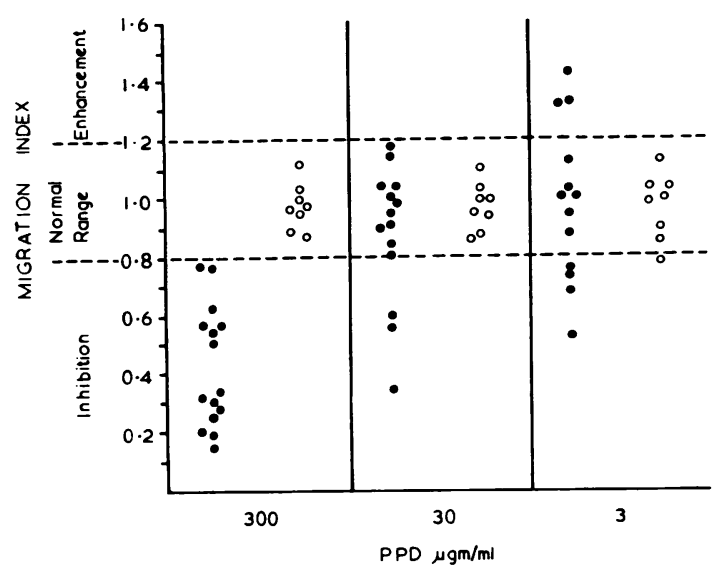

Fig. 2 Scattergram relating migration index of Mantoux-positive subjects (closed circles) and Mantouxnegative subjects (open circles) to concentrations of $P P D$ in the chamber. Each point represents the mean of four to six determinations. be excluded. A migration index of 0.8 therefore discriminated between Mantoux-positive and Mantoux-negative subjects (Student's $t$ test: $P<0.001$ ).

At $30 \mu \mathrm{g} / \mathrm{ml}$ PPD, some inhibition of migration was produced by the Mantoux-positive group, but this was not significant when compared with the Mantoux-negative group. At $3 \mu \mathrm{g} / \mathrm{ml}$ PPD, three of the Mantoux-positive subjects showed enhanced leucocyte migration (migration index greater than $1 \cdot 2$ ), suggesting that enhanced leucocyte migration (Smith, Eddleston, Dominguez, Evans, Bewick, and Williams, 1969) (see Fig. 1d) may be related to the concentration of antigen used in the migration test; again, at this concentration there was no significant difference between the reactivity of Mantoux-positive and Mantoux-negative subjects (Fig. 2, Table I).

The scattergram (Fig. 2) shows that the responses of the Mantoux-positive group were related to the concentration of antigen in the migration test but that no dose response relationships were obtained for the Mantoux-negative subjects.

\begin{tabular}{|c|c|c|c|c|c|}
\hline \multirow{2}{*}{$\begin{array}{l}\text { Subject } \\
\text { No. }\end{array}$} & \multirow{2}{*}{$\begin{array}{l}\text { Age } \\
(y r)\end{array}$} & \multirow{2}{*}{$\begin{array}{l}\text { Mantoux } \\
\text { Test }\end{array}$} & \multicolumn{3}{|c|}{ Migration Index with PPD at } \\
\hline & & & $300 \mathrm{\mu g} / \mathrm{ml}$ & $30 \mathrm{\mu g} / \mathrm{ml}$ & $3 \mathrm{\mu g} / \mathrm{ml}$ \\
\hline 1 & 56 & $1: 100$ & $0 \cdot 15$ & 0.35 & 0.53 \\
\hline 2 & 55 & $1: 1000$ & 0.19 & 1.04 & - \\
\hline 3 & 75 & $1: 1000$ & 0.20 & 0.60 & 0.75 \\
\hline 4 & 23 & $1: 1000$ & 0.26 & 0.55 & 068 \\
\hline 5 & 61 & 1:1000 & 028 & 0.81 & 0.88 \\
\hline 6 & 65 & $1: 1000$ & 0.31 & 0.91 & 0.95 \\
\hline 7 & 63 & $1: 1000$ & 0.32 & 0.90 & $1 \cdot 33$ \\
\hline 8 & 8 & $1: 1000$ & 0.34 & 0.90 & - \\
\hline 9 & 51 & $1: 1000$ & 0.51 & - & 1.00 \\
\hline 10 & 71 & $1: 1000$ & 0.55 & 0.95 & 1.00 \\
\hline 11 & 61 & $1: 1000$ & 0.57 & 1.00 & $1 \cdot 12$ \\
\hline 12 & 11 & $1: 100$ & 0.57 & 0.83 & 0.73 \\
\hline 13 & 75 & $1: 100$ & 0.63 & 1.04 & 1.43 \\
\hline 14 & 65 & $1: 100$ & 0.77 & $1 \cdot 18$ & 1.32 \\
\hline 15 & 19 & $1: 100$ & $0 \cdot 78$ & $1 \cdot 15$ & 1.03 \\
\hline \multicolumn{3}{|c|}{ Mean $\pm S D(1-15)$} & $0.43 \pm 0.21^{1}$ & $0.87 \pm 0.23^{2}$ & $0.98 \pm 0.27$ \\
\hline \multicolumn{3}{|c|}{$\begin{array}{l}t \text { Test of difference } \\
\text { from } 1.00\end{array}$} & $P<0.001$ & $P=0.025$ & $\begin{array}{l}\text { Not } \\
\text { significant }\end{array}$ \\
\hline 16 & 28 & Neg & 0.85 & 1.00 & 0.80 \\
\hline 17 & 80 & Neg & 0.87 & 0.87 & 0.99 \\
\hline 18 & 2 & Neg & 0.89 & 0.86 & 1.04 \\
\hline 19 & 6 & Neg & 0.96 & 0.94 & 0.89 \\
\hline 20 & $1 \frac{1}{2}$ & Neg & 0.98 & 1.00 & $1 \cdot 13$ \\
\hline 21 & 22 & Neg & 1.00 & 0.95 & 1.00 \\
\hline 22 & 18 & Neg & 1.03 & 1.03 & 1.04 \\
\hline 23 & $4 !$ & Neg & $1 \cdot 12$ & $1 \cdot 10$ & $0 \cdot 85$ \\
\hline \multicolumn{3}{|c|}{ Mean \pm SD (16-23) } & $0.96 \pm 0.14^{1}$ & $0.97 \pm 0.08^{2}$ & $0.96 \pm 0.11$ \\
\hline \multicolumn{3}{|c|}{$\begin{array}{l}t \text { Test of difference } \\
\text { from } 1.00\end{array}$} & $\begin{array}{l}\text { Not } \\
\text { significant }\end{array}$ & $\begin{array}{l}\text { Not } \\
\text { significant }\end{array}$ & $\begin{array}{l}\text { Not } \\
\text { significant }\end{array}$ \\
\hline
\end{tabular}

Table I Leucocyte migration indices in tuberculin sensitivity

Tests of differences between Mantoux-positive and Mantoux-negative

${ }^{1}$ At $300 \mu \mathrm{g} / \mathrm{ml}, \mathrm{P}<0.001$

At $30 \mu \mathrm{g} / \mathrm{ml}, P=0.15$ (not significant) 


\section{Discussion}

In the detection of tuberculin hypersensitivity in vitro the leucocyte migration test correlated with positive Mantoux reactions in every subject (15/15), and none of eight Mantoux-negative subjects gave a positive cell migration response. The equipment required for leucocyte migration is simple and readily available in clinical laboratories; the technique is easy and requires only about four hours to set up. This micro-technique circumvents recent criticism of leucocyte migration methods in tuberculin sensitivity (Kaltreider, Soghor, Taylor, and Decker, 1969). The test responds well to a soluble antigen, and we have found it eminently suitable for surveys of cellular hypersensitivity reactions using semisoluble and particulate antigens derived from human tissues and microbial preparations. At the cellular level, the test requires the participation of lymphocytes, as cell populations depleted of lymphocytes show no inhibition of migration with specific antigen (Søborg, 1969). Interaction between sensitized lymphocytes and specific antigen is an essential prerequisite to the demonstration of inhibition of migrating granulocytes, which act as 'target' or 'indicator' cells in the micro-environment of the chamber. Current evidence suggests that inhibition of granulocyte migration is brought about by soluble mediators generated by the lymphocytes; in clinical situations both non-antibody ('lymphokine') factors and antigen-antibody complexes may well mediate these effects (Dumonde, 1970). On this basis, it is not yet known whether the leucocyte migration test correlates only with delayed hypersensitivity. Our results in tuberculin sensitivity show that above a Mantoux-positive threshold (1:100 Old Tuberculin) the degree of migration did not correlate with the degree of delayed hypersensitivity in individual patients. There are two possible reasons for this discrepancy. First, the inflammatory mediators of delayed hypersensitivity may not be identical to the soluble factors which inhibit leucocyte migration. Second, delayed hypersensitivity and leucocyte migration inhibition may be affected to different degrees by coexisting humoral immune mechanisms. Indeed, the leucocyte migration test can be adapted to assessing the role of lymphokine factors and antigen-antibody complexes in clinical hypersensitivity states (Dumonde and Maini, 1971).

As a test of cellular hypersensitivity, the leucocyte migration technique has already been employed to investigate microbial infections, autoimmune states, and connective tissue diseases (Bendixen and Søborg, 1969; Williams, Brostoff, and Roitt, 1970; Maini, Stewart, and Dumonde, 1970), transplantation immunity (Smith et al, 1969), and clinical allergic states (Brostoff and Roitt, 1969). Our experience with the micro-technique reveals it to be more sensitive than methods previously employed; the test can be set up rapidly with the minimum of equipment, and utilizes only small quantities of $\frac{\bar{\sigma}}{\vec{D}}$ blood. The micro-technique is therefore suitable $\stackrel{\mathbb{D}}{\Omega}$ for use in children, and for the repeated monitoring $๗$ of cellular hypersensitivity in individual patients, $\vec{O}$ for example, in transplantation practice, during immunosuppressive therapy, and in immune de- $\vec{\omega}$ ficiency states. Furthermore, the reproducibility of this improved technique permits its routine applica- $\frac{8}{0}$ tion in clinical and epidemiological surveys.

We wish to thank volunteers who gave blood for this study. Blood specimens from children at St. 응 Mary Abbott's Hospital were obtained, with the parents' permission, at the same time as essential os investigations were being performed in the Paediatric $\frac{\mathbb{}}{8}$ Department.

Dr Konrad Federlin received a grant from the $\frac{3}{0}$ Deutsche Forschungsgemeinschaft. We thank the $\stackrel{\mathbb{D}}{-}$ Medical Research Council and the Arthritis and $\overrightarrow{0}$ Rheumatism Council for support for this work, and $\searrow$ Miss Enid Bowers for excellent technical assistance.

Reprint requests to Dr K. Federlin and within the U.K. only to Dr R. N. Maini, Division of Clinical Research, Kennedy Institute of Rheumatology, $\stackrel{\mathbb{Q}}{\overparen{Q}}$ London W6 7DQ.

\section{References}

Bendixen, G., and Søborg, M. (1969). A leucocyte migration technique for in vitro detection of cellular (delayed type) hypersensitivity. Dan. med. Bull., 16, 1-6.

Brostoff, J., and Roit t, I. M. (1969). Cell-mediated (delayed) hypersensitivity in patients with summer hay-fever. Lancet, 2, 1269-1271.

Dumonde, D. C. (1970). 'Lymphokines': Molecular mediators of cellular immune responses in animals and man. Proc. roy. Soc. 윽 Med., 63, 899-902.

Dumonde, D. C., and Maini, R. N. (1971). The clinical significance $ᄋ$ of mediat ors of cellular immunity. Clin Allergy, 1, 123-139.

Kalt reider, H. B., Soghor, D., Taylor, J. B., and Decker, J. E. (1969). D Capillary tube migration for detection of human delayed hypersensitivity: Difficulties encountered with 'buffy coat' cells and tuberculin antigen. J. Immunol., 103, 179-184.

Lockshin, M. D. (1969). Failure to demonstrate leukocyte migration o inhibition in human tuberculin hypersensitivity. Proc. Soc. N exp. Biol. $(N Y), 132,928-930$.

Maini, R. N., Stewart, S. M., and Dumonde, D. C. (1970). Peripheral W leucocyte migration inhibited by diphtheroid organisms $\sigma$ isolated from patients with rheumatoid arthritis. Ann. rheum. Dis. , 29, 541-545.

Smith, M. G. M., Eddleston, A. L. W. F., Dominguez, J. A., Evans, D. B., Bewick, M. , and Williams, R. (1969). Changes in leuco- $\mathscr{C}$ cyte migration after renal transplantation. Brit. med. J., 4, 275-278.

Søborg, M. (1969). 'Interaction of human peripheral lymphocytes and granulocytes in the migration inhibition reaction.' Acta $\vec{\Phi}$ med. scand., 185, 221-226.

Williams, M. H., Brostoff, J., and Roit t, I. M. (1970). Possible role $\frac{\overparen{P}}{\overparen{Q}}$ of mycoplasma fermentans in pathogenesis of rheumatoid arthrit is. Lancet, 2, 277-280. 